\title{
Strategy Development for Service-and-Innovative Not-for-Profit Organization (NPO): Practical Case
}

\author{
Sarawut Sujitjorn*, Raweewan Lertsuksombat \\ Synchrotron Light Research Institute (Public Organization), Nakhon Ratchasima, Thailand \\ Email: *sarawut.sujitjorn@slri.or.th
}

How to cite this paper: Sujitjorn, S. and Lertsuksombat, R. (2019) Strategy Development for Service-and-Innovative Notfor-Profit Organization (NPO): Practical Case. Open Journal of Business and Management, 7, 1641-1647.

https://doi.org/10.4236/ojbm.2019.74114

Received: August 1, 2019

Accepted: August 26, 2019

Published: August 29, 2019

Copyright $\odot 2019$ by author(s) and Scientific Research Publishing Inc. This work is licensed under the Creative Commons Attribution-NonCommercial International License (CC BY-NC 4.0). http://creativecommons.org/licenses/by-nc/4.0/

\begin{abstract}
This technical note reports a practical approach to design generic strategy, and strategy map appropriate for professional service-and-innovative organization. The available information herein is specific to Synchrotron Light Research Institute (SLRI)-Thailand, however useful and applicable to other organizations of a similar kind. Successful implementation of such strategies requires culture-based management.
\end{abstract}

\section{Keywords}

Not-for-Profit Organization, Balanced Scorecard, Strategy Map

\section{Introduction}

Synchrotron Light Research Institute (SLRI) is a not-for-profit organization (NPO) owned by the Government of Thailand. It provides synchrotron-photon experimental services to academics and industry. Its missions cover research and innovation, professional services based on synchrotron radiation, and technology transfer. More details on SLRI and its organizational structure are on the website http://www.slri.or.th. Management of the institute requires strategic planning and key-performance-indicators (KPIs) approved by the Board of Governance. As a governmental body, the institute has to have strategies responding to long-term national strategies. The institute has to choose a tool to aid its strategy development process. Even though several forms of tools are available [1] [2], science-based organization like SLRI rather prefers an explicit logic-based tool like balanced scorecard (BSC) [3]. BSC provides clear interactions between learning and growth, internal processes, customers, and financial dimensions. In other words, it states relationships from employees (learning and 
growth dimension) to customers, and financial success. Despite incomes for NPOs, more important KPIs of financial dimension are economic value added (EVA), and social return of investment (SROI). To achieve these KPIs, an effective marketing is vital for the success, albeit monetary incomes are not its main interest. At first sight, service provision and innovation seem to be disagreeing in some senses. When we consider closely, the type of services we offer to our savvy customers is analytical and research services, engineering design and consultancy. Under those circumstances, true collaboration among SLRI peers and clients is of prime importance. This is also the case with innovation. The innovation can be either evolutionary or revolutionary or both [4]. Working with savvy clients gives a lot more meanings to developing innovations with more chances of success. Therefore, scientific or professional services and innovation rely heavily on the same cultures namely collaboration, and cultivation cultures. Since professional services are timely and totally customer demanded, performances of our colleagues and peers must be goal oriented to a certain extent. This of course means that competence culture plays a part in organization's success but not as heavy as the first two. While we are a governmental body, we cannot drop down control or safety culture. This culture is implemented at the minimum level imposed by the government. Bearing in mind all these issues, CEO must pass them through to senior management team (SMT) and employees during brainstorming phases.

\section{Strategy Design via Document Research and Brainstorming}

A commonly well-known process for developing strategy starts with a predesigned vision and mission. The process goes through SWOT/TOWS analysis, synthesis of strategy and strategy map, designing KPIs, projects and actions or activities, respectively. To form a specific strategy for an organization, the analysis is necessary; it forms the basis for the synthesis action. There is unfortunately no short-cut. So, developing strategy is quite a tedious process, and sometimes time-consuming. To ease the strategic working group with this process, an organization may choose to collect relevant information from literatures, and design generic strategy at first. A collection of strategy and strategy map will come out as a result to be used further for a refinement. This refinement will need the results of SWOT/TOWS analysis that the working group and the SMT will spend time together for brainstorming to design specific strategy, and KPIs. For strategy developers, we recommend the materials in [1] [3] and [5] to begin with before working deeply in design details.

\section{Practical Case}

This technical note reports SLRI's practical approach to design generic strategy, and strategy map appropriate for professional service-and-innovative organization. We design our new vision as follows: "A Frontline Synchrotron Facility in 
Asia-Pacific in a Decade", and we reword our missions into a "triple helix". The triple helix is the key to marketing visibility, and composes of 1) innovating evolutionary and revolutionary products, and services, 2) developing research infrastructure for the country and ASEAN region, and 3) engaging our customers via branding and CRM activities. Metric for marketing visibility can be impacts of outcomes, customer advocacy, employee advocacy, and superfan, for instance. We surveyed existing literatures, and found out that there have been some proposed strategies for professional services and innovation as separate entities. For innovation, the book on "Creative Enterprise", volumes 1 and 3 strategy and execution, respectively, are comprehensive [6] [7] [8]. Readers can find useful materials concerning organization and strategy inside. Specific information on IT industry appears in [9]; it is applicable to other industries and NPOs. Additionally, an example of designing strategy for innovation is in [10]. For professional services, a large volume of relevant materials is available on media as publications, blogs, and so forth. References [11] [12] [13] provide directly useful information to the work. When strategy is being developed, developers have to think of KPIs subsequently. Some useful professional services KPIs can be found in [14] [15], while [9] provides those for research and innovation. Strategy developers have to apply the materials to suit their organization contexts. In our case, it is an NPO.

As a result of brainstorming of SMT and SLRI's sub-committee on strategy and risk management, we agreed with 2 generic strategies for innovation (IN1 and IN2), and the other 2 for services (SV1 and SV2) with their associate objectives and goals as follows:

Strategy IN1: Evolutionary or Incremental Innovation

Objectives:

1) To improve and enhance our organization

2) To achieve operational excellence

3) To deliver more values to our customers and employees

Goals:

1) Strategic alignment

2) Creativity and IP protection

3) Image and Brand

4) Business opportunity

5) Talent management

6) Operational excellence

Strategy IN2: Revolutionary or Radical Innovation

Objectives:

1) To achieve new performance limit

2) To gain better strategic position of the organization

3) To achieve new market

Goals:

1) Strategic alignment

2) Talent management 
3) Operational excellence

4) Collaborative network

5) Leader in technology and innovation

Strategy SV1: Non-proprietary services

Objectives:

1) To support national academic research agendas

2) To build and strengthen collaborative networks

Goals:

1) Team development

2) IT and information

3) Service culture for operational excellence

4) Growth via organizational cultures

5) Customer satisfaction

6) Collaboration with clients

Strategy SV2: Proprietary services

Objectives:

1) To achieve EVA at national level

2) To leverage national competitiveness

3) To improve service efficiency

Goals:

1) Team development

2) IT and information

3) Efficient and responsive services

4) Customer engagement

5) Brand loyalty

6) More incomes

7) EVA and SROI

Note that some goals are common, so merging them results in a set of 11 different goals. There are still 4 generic strategies, which complement each other.

Referring to Figure 1, all 11 goals are embedded. Arrows with solid and dashed lines represent strong and weak links, respectively. The links can be either one or two ways. The bottom of the figure shows weighted 4 types of culture, i.e. employees come first with collaboration and cultivation cultures as first priority; competence comes second; control culture comes third. This is due to collaboration and cultivation cultures are of prime importance for services and innovation missions, while goal-oriented or competence culture does help service mission. As our institute is owned by the government, safety and control culture is compulsory. All these cultures must be implemented with suitable weights and interactions, and practically managed properly.

Referring to the learning and growth perspective, according to the solid arrows in upward directions, the three goals directly serve the goals in the internal process perspective. Laterally, a two-way link between the cultural reinforcement and the talent management goals is possible under a weak situation. Hence, the dashed arrow means that the two do not serve but support each other. The other 


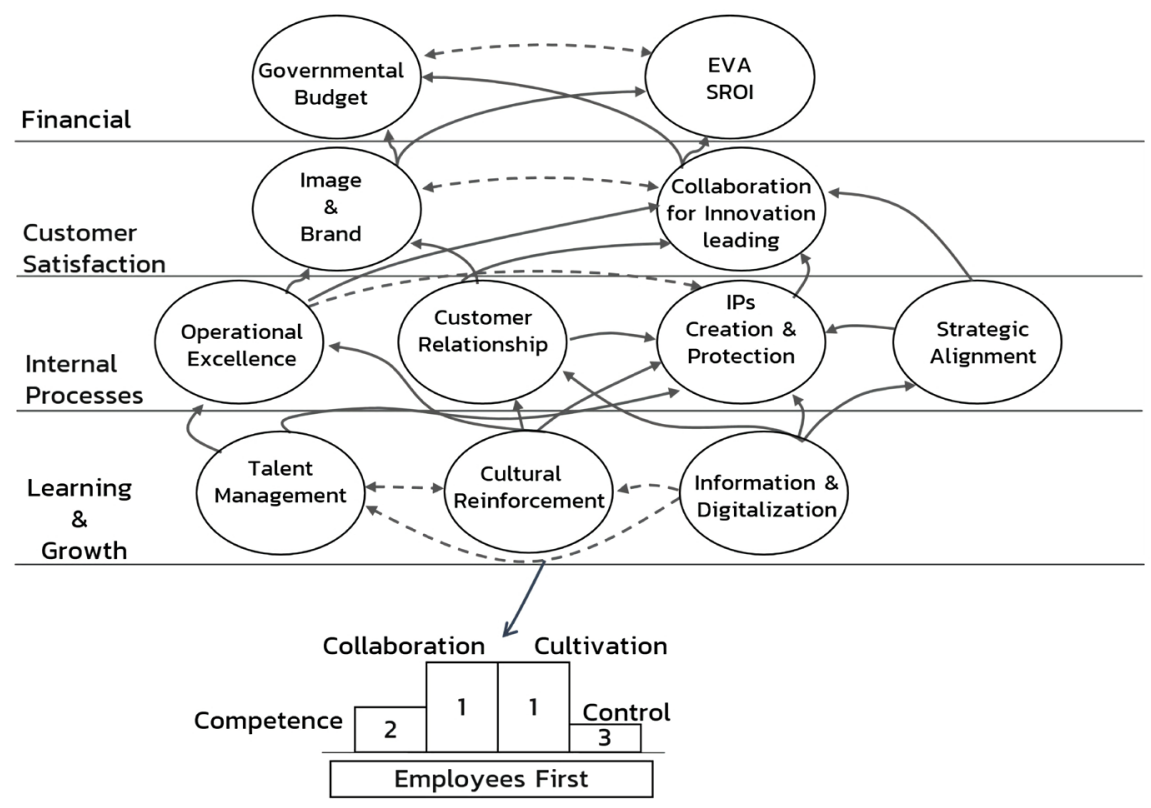

Figure 1. Strategy map of a service-and-innovative organization.

two one-way lateral links, i.e. from the information and digitalization to the cultural reinforcement, and the talent management, respectively, means that one plays support roles to the other two goals. Readers can apply this principle to clarify their understanding of the whole diagram. A clear understanding is important for designing projects, activities, and KPIs. Note that strategic alignment goal, the backbone of a successful organization, means witty decisions and implementations of management including resource allocations, etc.

\section{Findings and Discussion}

We have proposed a strategy map with 11 goals for a service-and-innovative organization. It can be applied to companies and NPOs. For business, a company can simply replace the governmental budget goal with an income goal. An NPO is more interested in economic, environmental, and societal impacts in terms of EVA and SROI. The map comes with 2 generic strategies for innovation (IN1 and IN2), and the other 2 for services (SV1 and SV2). The strategies read as follows: IN1-evolutionary or incremental innovation, IN2-revolutionary or radical innovation, SV1-non-proprietary services, and SV2-proprietary services. As simple they may seem, the organizations will have to think divergently based on their vision and corporate goals on what kinds of innovation they want to achieve, and what service domains they are in. Readers may rethink of our triple helix mentioned in Section 3. During our development phase, we worked out so hard to specify the types of innovation we wanted to achieve, and to specify and clarify our blue-ocean marketing tactics, and CRM activities. We have found that professional services and innovation missions share similar main cultures for success, i.e. collaboration, and cultivation. A true collaboration between employees and clients to deliver a collectively witty solution, and an effective mar- 
keting are keys to success. Furthermore, the competence and the control cultures cannot be dropped out. They have to be implemented with some suitable weights. For an NPO, the competence culture comes second, while the control culture comes third.

\section{Conclusion}

This technical note has presented generic strategies, associate goals and strategy map for a service-and-innovative not-for-profit organization as a result of document research and brainstorming. Due to its logical exposition, BSC has been chosen to guide our development process. We arrived at 4 generic strategies, and 11 goals with a solid belief in employee first metaphor. However, the concept of internal customers is absolutely discouraged. The two corporate cultures of prime importance are collaboration, and cultivation. The proposed information is ready to use by any organizations providing professional services, and conducting research and innovation as their missions.

\section{Acknowledgements}

The authors thank SLRI's sub-committee on strategy and risk management, and their senior management team for valuable brainstorming. Preparation of the illustration by Phakamart Kruasri is greatly acknowledged.

\section{Conflicts of Interest}

The authors declare no conflicts of interest regarding the publication of this paper.

\section{References}

[1] Mintzberg, H., Ahlstrand, B. and Lampel, J. (1998) Strategy Safari. Free Press, New York.

[2] Parmenter, D. (2015) Key Performance Indicators-Developing, Implementing, and Using Winning KPIs. 3rd Edition, Wiley, Hoboken. https://doi.org/10.1002/9781119019855

[3] Kaplan, R. and Norton, D. (1996) Translating Strategy into Action-The Balanced Scorecard. HBS Press, Boston. https://doi.org/10.1108/eb054566

[4] Brown, T. (2019) Change by Design. Harper Business, New York.

[5] Evans, V. (2014) 25 Need-to-Know Strategy Tools. Pearson, London.

[6] Davila, T. (2007) The Promise of Management Control Systems for Innovation and Strategic Change. In: Davila, T., Epstein, M.J. and Shelton, R., Eds., The Creative Enterprise-Volume 1 Strategy, Praeger Perspectives, Westport, 181-192.

[7] Epstein, M.J. (2007) Drivers and Measures of Innovative Success. In: Davila, T., Epstein, M.J. and Shelton, R., Eds., The Creative Enterprise-Volume 3 Execution, Praeger Perspectives, Westport, 55-76.

[8] Sauter, R. (2007) Management of Innovation and Product Development Process. In: Davila, T., Epstein, M.J. and Shelton, R., Eds., The Creative Enterprise-Volume 3 Execution, Praeger Perspectives, Westport, 229-243. 
[9] Samsonowa, T. (2012) Industrial Research Performance Management. Verlag Springer, Berlin. https://doi.org/10.1007/978-3-7908-2762-0

[10] Balanced Scorecard Institute (2000) Build Innovation into Your Strategy.

[11] Canavan, D., Scott, P.S. and Magematin, V. (2013) Aligning Strategy and Talent in Creative Professional Service Firms. Journal of Business Strategy, 34, 24-32. https://doi.org/10.1108/JBS-10-2012-0058

[12] Ross, B. and Segal, C. (2002) Breakthrough Thinking for Nonprofit Organizations. Willey, Hoboken.

[13] Sage Intacct. (2018) Top 5 Success Metrics for Professional Services Organizations.

[14] David, M. (2017) 5 KPIs Every Professional Services Firms Should Track.

[15] Urich, J. (2013) What Are the Essential KPIs for Professional Services Organization. 